Abstract Individuals with autism spectrum disorder (ASD) often display impairments in creativity, yet savant artists with ASD are reported to produce highly novel and original artistic outputs. To explore this paradox, we assessed nine savant artists with ASD, nine talented art students, nine non-artistically talented individuals with ASD, and nine individuals with mild/moderate learning difficulties (MLD) on tasks in and out of their domain of expertise. This was to ascertain whether the performance of the savant artists was related to their artistic ability, their diagnosis of ASD or their level of intellectual functioning. Results demonstrated that the responses of the art students were more creative (as assessed on measures of fluency, originality, elaboration and flexibility) than the savant, ASD and MLD groups on a drawing task. Although the savants did produce more elaborative responses than the ASD and MLD groups, no differences were observed on the other indices of creativity. On a non-drawing task, the savants produced more original outputs than the ASD and MLD groups (scoring similarly to the art students), but group differences were not observed on the other measures.

Keywords autism, savants, creativity, domain-specificity, talent 


\section{Creativity in savant artists with autism}

The term 'savant' was originally used to describe individuals who had low levels of intelligence, accompanied by an outstanding ability in a specific area (Down, 1887); a definition that was later extended to include individuals with average or above average intelligence (Miller, 1999). The majority of savants are diagnosed with autism spectrum disorder (ASD) (Pring, 2005), with savant abilities being found in around 10-30\% of this

group (Rimland, 1978; Howlin et al., 2009; Bölte and Poustka, 2004). Savant talents have been documented in a wide range of domains, including music (Sloboda et al., 1985), calendar calculation (Cowan and Frith, 2009), arithmetic (Heavey, 2004), poetry (Dowker et al., 1996), memory (Treffert, 2009) and, the focus of this paper, art (Hermelin and O'Connor, 1970).

Whilst artistic ability is not the most prolific of savant skills (Hill, 1978), it is perhaps the most commonly documented. One of the most well-known descriptions of this ability was provided by Selfe $(1977 ;$, 1983) in her reports of child artist Nadia. Diagnosed with autism when she was six years old, Nadia possessed no language skills and poor comprehension. However, at the age of three and a half, she developed an amazing capacity to draw. These drawings were sophisticated, largely focusing on animals, but also including depictions of people, trains and other objects. Impressively, she was able to generate these images from memory and never made mistakes or used an eraser (as also noted in the savant draughtsman EC, Mottron and Belleville, 1995). She also displayed the use of complex graphic strategies (e.g., linear perspective, 
foreshortening, occlusion, proportioning), which are not usually apparent in artistic output until much later life, all without formal artistic training.

Such accounts led Hermelin and O'Connor (and later, Pring) to initiate a comprehensive programme of experimental research on this group (see Hermelin, 2002, for an overview). By comparing the performance of savant artists with non-talented comparison groups matched for intelligence quotient (IQ), or gifted individuals with no cognitive impairments, these researchers attempted to isolate the component aspects related to specific abilities or to talent in general. Importantly, these studies highlighted the domain-specific nature of savant talent, with superior performance only being observed on drawing or construction tasks (O'Connor and Hermelin, 1987; Pring et al., 2010; Crane et al., forthcoming).

Despite several studies exploring the nature of savant artistic talent, a key domain that has been overlooked in this group is creativity - the ability to produce outputs that are novel (original or unexpected) and adaptive (useful or within the constraints of a task) (Sternberg and Lubart, 1999). The creative nature of savant art has, however, been mentioned by a number of researchers. Sacks (1995), for example, noted that savants' outputs are rarely exact replications of the original image and must go through some sort of transformation. Selfe $(1977 ;, 1983)$ also reported that Nadia was able to draw images from a variety of perspectives, introducing a variety of omissions and additions. Despite this, Nettelbank and Young (1996) argue that in areas in which artistic creativity is permitted, outputs produced by savants are often mechanical, with low levels of expressiveness and emotional involvement. Indeed, savant artists often draw from a 
restricted range of categories, usually in their circumscribed area of interest (Treffert, 2009). However this is not very different from accomplished artists throughout history. To date, only one group study has attempted to assess creativity in savants. Using the Torrance Test of Creative Thinking (TTCT) (Torrance, 1974), Duckett (1976) assessed creativity in savants (with a variety of talents) relative to a comparison group matched for age, gender and IQ. Interestingly, Duckett's prediction that the savant group would score highly on measures of fluency, flexibility and originality was not supported. Although the savants did score high on elaboration, these scores were still below mental age equivalent norms. More interestingly, high levels of elaboration were only found in the calendar calculators - an ability not obviously related to creativity. Unfortunately, no other information is available from this study, especially with regards to the diagnoses of the participants. At the time of this study, very little was known regarding the generative deficits in ASD (cf. Turner, 1999). However, if Duckett's group of savants were similar to those recently documented with regard to the incidence of ASD (up to 30\%) (Pring, 2005; Howlin et al., 2009), it is likely that the results would have been confounded by a lack of diagnostic matching.

Since Duckett's study, there have been no attempts to measure creative behaviour in such a standardised or scientific manner. The aim of the current study was to assess creativity in savant artists using standardised tests, both in and out of their domain of expertise. The savants were compared to a group with ASD, a group with mild/moderate learning disabilities (MLD) and a group of talented art students with no developmental disabilities. It was hypothesised that if the savant artists did display any creative outputs, it would be in their domain of expertise (cf. O'Connor and Hermelin, 1987). However, 
due to the novelty of the study, no specific predictions were made regarding performance in creativity sub-domains in any of the groups.

\title{
Method
}

\section{Participants}

Four groups of participants were included in this study: nine savant artists with ASD, nine non-talented comparison adults with ASD, nine non-talented adults with MLD, and nine artistically talented students. See Table 1 for participant demographics.

\author{
[place Table 1 about here]
}

The savant artists had all received a diagnosis of ASD from a psychologist or psychiatrist (five with autism, three with Asperger syndrome and one with atypical autism) prior to participation in the current research. These diagnoses were made through observations of the individual, as well as parental reports. The savant artists were recruited from a variety of sources, including an existing database of graphically gifted savants, specialist services affiliated to the National Autistic Society, and by contacting savant artists following local art exhibitions. Upon recruitment into the study, examples of artwork from each savant were assessed by an independent art examiner, who rated the work of all savants as being of a standard that would confer entry into art school (see Figure 1). As for all groups in this study, the mean verbal IQ (VIQ) of the savants was assessed using the Peabody Picture Vocabulary Test (PPVT) (Dunn and Dunn, 1997), 
and their mean performance IQ (PIQ) was assessed using Raven's Standard Progressive Matrices (Raven, 1960) or Coloured Progressive Matrices (Raven, 1956).

[place Figure 1 about here]

The ASD comparison group comprised five adults with autism, three with Asperger syndrome and one with atypical autism. At the time of testing, these participants attended an adult day centre run by the National Autistic Society. Criteria for inclusion in the day centre included a formal diagnosis of ASD based on clinician observations and standardised assessments. None of these participants displayed any artistic talent, although several took part in art sessions at their day centre. These adults were individually matched to the savant artists for age (within three years), gender, and IQ (within three IQ points).

The MLD group comprised eight adults with a variety of developmental disorders and general learning difficulties. A brief screening measure, adapted from the Autism Diagnostic Observation Schedule (Lord et al., 1989) was used to ensure that none of the participants in this group had an undiagnosed ASD. These participants were recruited from a local adult education centre. Although individuals with mild/moderate learning disabilities tend to have IQs of around 50 to 70 (Wechsler, 1999), one further participant (recruited from the University of London) was included in this group, to match the relatively high IQ of one of the savants (whose mean VIQ was 111 and PIQ was 114). Although the VIQ of the MLD group is slightly higher than that of the two groups with ASD (savant and non-savant), this difference did not reach statistical significance ( $p>$ 
$.05)$. The MLD group was individually matched to the savants for age (within three IQ points), gender and PIQ (within three IQ points). None of this group displayed any artistic ability.

The artistically talented group comprised 'A' Level art students who were selected for inclusion in the study by their art teacher. The art students were in the top $10 \%$ of their year for artistic ability and were consistently receiving A and B grades for their coursework. Each had previously received an A or B grade for their GCSE art course. These participants were younger than the other groups as, although several of the savant group received formal training in art, this would not compare to the training of adult professional artists. The art students and savants also spent a comparable amount of time on their artwork (approximately ten hours per week), and the output of the art students was judged to be of a similar standard to that of the savants by an independent art examiner.

\section{Materials}

To explore creativity in the savants' domain of expertise, the incomplete and repeated figures tasks of the Torrance Test of Creative Thinking (TTCT) (Torrance, 1974) were used. In the incomplete figures task, participants were presented with ten meaningless squiggles and were instructed to make each of the squiggles into a picture; drawing anything they wanted, as long as they used the squiggle within the picture. Participants were also asked to provide a title for each picture. Each appropriate response was congratulated, and each inappropriate response (not incorporating the squiggle into the picture, repeating a previous response) resulted in a warning (i.e., a reminder of the 
task instructions). If participants could not complete an item, they were told to move onto the next item, with the opportunity to complete any omitted figures at the end. No time restriction was imposed. A training period was also included, prior to the experimental trials, to establish that the instructions had been fully understood, and to stress the need for a different response on each trial. This also ensured optimal performance in the mixed ability groups (Leevers and Harris, 1998).

In the repeated figures condition, participants were presented with ten sets of parallel lines (of equal length), three different widths apart; two at $8 \mathrm{~mm}$ apart, followed by four sets at $13 \mathrm{~mm}$ apart, and four sets at $20 \mathrm{~mm}$ apart. Participants were instructed to make each pair of lines into a representational and named picture. A training period was also included, in which participants were instructed to produce pictures from three triangles.

Responses on the incomplete and repeated figures tasks of the TTCT were scored on four dimensions: fluency, originality, elaboration and flexibility. The fluency score comprised the total number of responses completed by each participant. Participants were assigned a mark for each trial in which they made an attempt to incorporate the stimulus figure into a picture. This included responses in which the picture did not resemble the title, as well as abstract patterns and designs. The only responses not included within this score were those in which the participant scribbled on the response booklet or simply redrew the stimulus figure. This scoring scheme therefore identifies genuine generativity deficits, irrespective of the appropriateness of the response. The fluency measure was a closed task, as the stimuli comprised 20 (ten incomplete and ten repeated) figures. 
Originality was scored by assigning each response a rating of statistical rarity, based on a set of standardised norms (all of the norms provided in the TTCT are based on the scores of an adult student sample; see Torrance, 1974, for further information). In the incomplete figures task, commonplace responses received a score of zero, the most original responses were assigned a score of two, and those falling in between received a score of one. For the repeated figures task, responses were scored on a scale of zero to three (ranging from commonplace to highly original responses), according to a second set of standardised norms. To ensure that low levels of responding did not confound originality scores, a fluency-independent measure of originality was derived, by dividing the total originality score by the total fluency score in each condition (incomplete and repeated).

Elaboration measures the amount of detail added to a drawn response, thereby representing the participant's ability to carry out and develop an idea. Credit was given for each new pertinent and meaningful detail added to the original stimulus figures. Therefore, if a participant drew a tree and added several identical leaves, they would only score one point for elaboration. In contrast, if they drew a tree with a variety of types of leaf, they would be given credit for each variety of leaf. The total elaboration score was divided by the total fluency score, to provide a fluency-independent measure of elaboration.

Flexibility measures the ability to produce ideas that are semantically different. Here, each response was included in an overall semantic category (e.g., clothing, buildings) and the flexibility score comprised the total number of semantic categories. The flexibility dimension was therefore closed, as it was possible for participants to score 
at ceiling level if they produced 20 semantically different responses (ten in the incomplete condition, and ten in the repeated condition). Whilst a fluency-independent measure of flexibility could be obtained (by calculating the percentage of category scores with respect to the total number of responses), this would result in those who produced fewer responses overall gaining higher scores (as the fewer responses given, the easier it would be to make these semantically different). Therefore, raw flexibility scores were used.

To explore creativity outside of the savants' domain of expertise, a figural synthesis task (FST) was used. In this task, participants were presented with eight shapes (taken from Finke and Slayton, 1988), which comprised five common geographical figures (square, triangle, rectangle, circle, semi-circle) and three other shapes (a cross, letter J, figure eight). Pilot data suggested that these could be easily incorporated into a variety of designs. The stimuli were quasi two-dimensional (so they were more akin to pictorial representation) and ranged from $80 \mathrm{~mm}$ in length to $80 \mathrm{~mm}$ in width (see Figure 2).

[place Figure 2 about here]

A training task was completed first, followed by the two, three and four figure conditions. The experimenter laid the shapes in front of the participant and, for the first condition (two figures), showed participants the semi-circle and letter J. Participants were told that the purpose of this task was to add the two shapes together to form a recognisable, named representation. The experimenter demonstrated this by placing the semi-circle on top of the figure J. All participants could correctly identify this as an 
umbrella or the letter J. The two shapes were then returned to the remaining six and participants were instructed to see what they could make using two shapes at a time. They were told that they had to produce responses that 'looked like real things' and to name each response. Participants were given five minutes to generate as many responses as possible and two warnings were given if an error was made (e.g., an incorrect number of shapes was used, the response did not resemble the given title). Following the two-figure condition, participants completed three and four shape versions of the task.

The FST was scored on measures of fluency (total and representational) and originality. The total fluency score referred to the number of responses produced and named by participants, including any repeats or errors. Representational fluency assessed responses that were clearly recognisable as a representation of the title they were given. This measure was derived by asking three independent examiners to score each response according to how well the pattern corresponded to its title. If two of the three examiners scored a response as recognisable, it was included in the representational fluency score.

To assess originality, three independent judges scored responses on how original the representations, and not the titles, were. Although an original title would often be accompanied by an original representation, scoring the representations meant that original representations of common words could be credited. As before, a response was deemed original if it was scored in this category by two out of three judges. As scores must be recognisable in order to be original, a fluency-independent measure of originality was derived (by dividing originality scores by representational fluency scores).

\section{Procedure}


Each participant was tested individually in a quiet room at their home or day centre, with the exception of the art students, who were tested in small groups at their sixth form college. On the TTCT, participants were informed that they would be completing a test of creativity, in which they would be producing a variety of pictures. They were reminded that this was not a test of drawing ability. Therefore, the quality of their drawings was not important, but what they drew. Following a training period, participants completed the incomplete figures task and then the repeated figures task. Following this, the FST was completed. Frequent breaks were taken throughout the tasks (by participants in all groups), in which the participants returned to their previous activities.

\section{Results}

Data from the TTCT and FST were analysed using analyses of variance (ANOVAs) and t-tests, unless parametric assumptions were violated. In these instances, non-parametric analyses (Kruskall-Wallis and Wilcoxon Signed Ranks tests) were employed.

Creativity in the savants' domain of expertise: On the TTCT, the art students performed significantly better than the other three groups. Therefore, the data of this group is included in the results section for descriptive purposes only, to reduce the overall number of statistical comparisons.

Fluency: The number of responses produced. As the pattern of results for the incomplete and repeated figure conditions was similar (see Table 2), the total fluency 
score was analysed. No significant differences were observed between the three groups on this measure, $F(2,32)=1.70, p>.05$.

[place Table 2 about here]

Originality: The novelty of the response. Two Kruskall-Wallis tests examining originality demonstrated that there were no significant differences between the three mixed-ability groups in the incomplete $\left(\chi^{2}=0.46, p>.05\right)$ or repeated $\left(\chi^{2}=0.79, p>.05\right)$ figure conditions (see Table 2).

Elaboration: The addition of detail. Elaboration scores are illustrated in Table 2. Regarding the incomplete figures condition, a Kruskall-Wallis test demonstrated that there was no significant difference between the scores of the three mixed-ability groups $\left(\chi^{2}=3.20, p>.05\right)$. In contrast, a significant group effect was observed for the repeated figures condition $\left(\chi^{2}=7.25, p<.05\right)$. This was due to the savant artists producing significantly more elaborative responses than the ASD $(W=14.50, p<.025)$ and MLD $(W=14.5, p<.025)$ groups.

Flexibility: The ability to switch conceptual set. There was no significant difference between the performance of the three groups on the flexibility measure, $F(2$, $24)=1.05, p>.05$ (see Table 2$)$. However, a significant effect of condition was observed, $F(1,24)=8.79, p<.01$, as all groups produced fewer flexible responses on the repeated, relative to the incomplete, figure condition. A non-significant interaction, $F(2$, $24)=.03, p>.05$, suggested that this effect was consistent across groups. 
Creativity outside of the savants' domain of expertise (figural synthesis):

Fluency: The number of responses produced. A 3 (condition: two, three, or four figure) x 4 (savants, ASD, MLD, art student) mixed design ANOVA examining overall fluency scores (see Table 3) revealed there to be a significant main effect of condition, $F$ $(2,64)=29.75, p<.01$. Within participant contrasts revealed a significant linear trend, $F$ $(1,32)=62.38, p<.01$, indicating that all groups produced fewer responses as the number of figures increased. A main effect of group was also observed, $F(1,32)=$ $119.38, p<.05$. Although the difference between the savant and MLD groups did not reach significance, $t=-1.78, p=.09$, the art students produced a higher number of responses than the savant group, $t=2.29, p<.05$. There was no difference between the two groups with ASD (savant and non-savant), $t=1.14, p>.05$, nor was a significant interaction effect found, $F(6,64)=.80, p>.05$.

[place Table 3 about here]

Representational fluency: The number of recognisable responses produced. A mixed design ANOVA analysing the percentage scores (representational fluency/total fluency) of the three groups (see Table 4) revealed significant main effects of group, $F$ ( 3 , $32)=521.01, p<.01$, and condition, $F(2,64)=12.44, p<.001$, as well as a significant interaction effect, $F(6,64)=2.71, p<.05$. Due to the low sample size and the large standard deviations in all conditions, within group comparisons were conducted. In addition, only the two and four figure conditions were compared, to reduce the number of comparisons made. Further, no adjustments were made for multiple comparisons, as this 
may mask any differences (although it is accepted that this does increase the probability of a Type I error). These results demonstrated that the savant $(t=4.07, p<.001)$ and ASD groups $(t=2.20, p<.05)$ produced fewer representational responses in the four figure, relative to the two-figure, condition.

[place Table 4 about here]

Originality: The novelty of the response. A Wilcoxon test examining differences between the two and four figure conditions revealed that there were no significant differences in any of the groups on the originality measure $(p s>.05)$ (see Table 5). Kruskal-Wallis analyses indicated that there were no significant group differences on the two $\left(\chi^{2}=1.54, p>.05\right)$ or three $\left(\chi^{2}=1.18, p>.05\right)$ figure conditions. However, there was a significant difference on the four-figure condition $\left(\chi^{2}=7.88, p<.05\right)$. Further analyses indicated that the originality scores of the savant did not differ from those of the ASD group $(\mathrm{W}=24.0, p>.05)$, although this effect did approach significance in the MLD group, in that the savants appeared to produce a higher number of original outputs than the MLD group $(\mathrm{W}=24.0, p=.09)$. Whilst the art students did not significantly differ from the savants on this condition, they did produce significantly more original responses than the $\operatorname{ASD}(\mathrm{W}=13.0, p<.01)$ and $\operatorname{MLD}(\mathrm{W}=13.0, p<.01)$ groups.

[place Table 5 about here]

Discussion 
This study assessed savant artists (relative to art students, adults with ASD, and adults with MLD) on standardised creativity tests that were either related or unrelated to their domain of expertise. On a drawing task, the art students produced more creative outputs than the savant, ASD and MLD groups. The savants did, however, produce more elaborate responses than the ASD and MLD groups. On the non-drawing construction task, the savant group produced more original (and not more fluent) outputs than the ASD and MLD groups (scoring similarly to the art students).

The first notable finding from this study was that the savants scored higher than the ASD and MLD groups on the elaboration measure of the TTCT, suggesting that elaboration is a key skill in savant artistic talent. This raises the question of which aspects of the savants' drawing ability allows them to produce more elaborate responses than the MLD and ASD groups? One explanation concerns manual dexterity. On the TTCT, superior manual dexterity would allow the savant group to produce more detailed responses than the MLD or ASD groups. This is consistent with O'Connor and Hermelin's (1987) suggestion that enhanced motor control is a primary feature of savant talent (see also Pring et al., 2010) and concords with Hermelin, Pring and Heavey's (1994) finding of enhanced motor control (on drawing and non-drawing tasks) in savant artists. However, it is unlikely that manual dexterity alone can account for the savants' superior elaboration, as the art students produce more elaborative responses than the savants. It should also be noted that elaboration referred to each new idea incorporated within the design, therefore indexing generativity. Potentially, repetitive and obsessive preoccupation is linked to low elaboration scores in the art groups. 
Interestingly, the current study did not find evidence of a generativity deficit in savant artists, as fluency and flexibility scores were similar to those of the IQ-matched groups. Although one might expect the performance of the MLD group to be higher than that of the groups with ASD (savant and non-savant), considering the generativity problems commonly noted in ASD (Turner, 1999), it is likely that the closed nature of the task contributed to this finding (see White et al., 2009; Kenworthy et al., 2008). Although an open-ended task might have identified subtle differences in performance between the savant, MLD and ASD groups, a limit was imposed on the number of responses that participants could provide to prevent these measures impacting on the other factors assessed in this study (e.g., originality). Further research is necessary to explore the generative abilities of savant artists with ASD in greater depth.

The current study also found that the savants did not score higher than the ASD or MLD groups on the originality measure of the TTCT. Given the high level of artistic talent displayed by the savants, one might presume that, of all the domains assessed in the TTCT, the savants would score highly on originality. One explanation is that savant artists produce unoriginal responses because they cannot generate drawings 'on instruction'. However, related to this they do tend to draw in specific categories of interest (Treffert, 2009), displaying 'stylistic sameness' (Cardinal, 2009). Nevertheless, this finding is very puzzling considering that the savants scored highly on the originality measure of the FST - a task outside of the savants' domain of expertise.

This disparity might be due to the TTCT and FST defining and measuring originality in different ways. On the TTCT, originality was scored on the basis of frequency; whilst the task depended on a drawn response, it was the title of the response 
that was compared to standardised norms. In this way, the task was confounded by verbal ability, with no accommodations being made for unusual representations of common titles. In contrast, the FST emphasised perceptual aspects of the figure, with responses scored as common or unusual depending on the visual representation, rather than the title. As such, the FST can be seen as a purer measure of perceptual originality.

The finding that savants might display a high level of originality on the FST conflicts with O'Connor and Hermelin's (1987) suggestion that savant talent is domainspecific. However, this might be because the FST, despite not requiring a drawn response, is based on imagery. As such, this task is closer to being in the savants' domain of expertise than being a measure of domain-general processing. In addition, it is difficult to directly compare the results of the TTCT and FST, as the nature of the responses required on these tasks is rather different. Whilst the TTCT is rather unconstrained, assessing participants' ability to complete a series of figures in any way possible, the FST has a restricted range of responses. As individuals with ASD perform better on constrained tasks (White et al., 2009), this might account for the lack of original responses from the savants on the TTCT.

Finally, it is important to stress the methodological limitations of the current research. First, there is considerable debate regarding the definition and assessment of creativity (Chamorro-Premuzic, 2007). There have also been concerns raised regarding the TTCT, including whether it has any predictive validity (Torrance, 1972). Although this is the most widely used measure of creativity and has been extensively researched, it is important for future research to explore other indices of creativity in savant artists. A second methodological issue regards the limited sample size in the current study. 
Although it is therefore important to treat the results with caution, this must be balanced against the rarity of the sample. Savants are a rare group of individuals, yet alone a group of savants with the same special skill. We hope this initial research stimulates further investigation into this topic. 


\section{Acknowledgements}

We would like to thank the savant and control participants who took part in this study, as well as their parents and caregivers. Thanks also go to the SAND centre in Gravesend (especially to Jan Cotton), the LEAP centre in Ealing and the Oakfield centre in Anerley for their assistance with recruitment. 


\section{References}

Bölte S and Poustka F. (2004) Comparing the intelligence profiles of savant and nonsavant individuals with autistic disorder. Intelligence 32: 121-131.

Cardinal R. (2009) Outsider Art and the autistic creator. Philosophical Transactions of the Royal Society B: Biological Sciences 364: 1343-1480.

Chamorro-Premuzic T. (2007) Personality and individual differences, Oxford: Blackwell.

Cowan R and Frith C. (2009) Do calendrical savants use calculation to answer date questions? A functional magnetic resonance imaging study. Philosophical Transactions of the Royal Society B: Biological Sciences 364: 1417-1424.

Crane L, Pring L, Ryder N, et al. (forthcoming) Executive functions in savant artists with autism. Research in Autism Spectrum Disorders.

Dowker A, Hermelin B and Pring L. (1996) A savant poet. Psychological Medicine 26: 913-924.

Down J. (1887) On some of the mental affections of childhood and youth, London: Churchill.

Duckett JM. (1976) Idiot savants: Super specialization in mentally retarded persons. University of Texas at Austin.

Dunn L and Dunn L. (1997) Peabody Picture Vocabulary Test, Circle Pines, MN: American Guidance Service.

Finke RA and Slayton K. (1988) Explorations of Creative Visual Synthesis in Mental Imagery. Memory and Cognition 16: 252-257.

Heavey L. (2004) Arithmetical savants. In: Baroody A and Dowker A (eds) The development of arithmetic concepts and skills: Recent research and theory. Oxford: Oxford University Press.

Hermelin B. (2002) Bright splinters of the mind: a personal story of research with autistic savants, London: Jessica Kingsley.

Hermelin B and O'Connor M. (1970) Psychological experiments with autistic children, Oxford: Pergamon Press.

Hermelin B, Pring L and Heavey L. (1994) Visual and motor functions in graphically gifted savants. Psychological Medicine 24: 673-680.

Hill AL. (1978) Savants: Mentally retarded individuals with special skills. In: Ellis N (ed) International review of research in mental retardation. New York: Academic Press, 277-298.

Howlin P, Goode S, Hutton J, et al. (2009) Savant skills in autism: psychometric approaches and parental reports. Philosophical Transactions of the Royal Society B: Biological Sciences 364: 1359-1368.

Kenworthy L, Yerys BE, Anthony LG, et al. (2008) Understanding executive control in autism spectrum disorders in the lab and in the real world. Neuropsychology Review 18: 320-338.

Leevers HJ and Harris PL. (1998) Drawing impossible entities: A measure of the imagination in children with autism, children with learning disabilities, and normal four-year-olds. Journal of Child Psychology and Psychiatry 39: 399-410.

Lord C, Rutter M, Goode S, et al. (1989) Austism diagnostic observation schedule: A standardized observation of communicative and social behavior. Journal of Autism and Developmental Disorders 19: 185-212. 
Miller L. (1999) The savant syndrome: Intellectual impairment and exceptional skill. Psychological Bulletin 125: 31-46.

Mottron L and Belleville S. (1995) Perspective production in a savant autistic draughtsman. Psychological Medicine 25: 639-648.

Nettelbank T and Young R. (1996) Intelligence and the savant syndrome: Is the whole greater than the sum of the fragments? Intelligence 22: 49-67.

O'Connor N and Hermelin B. (1987) Visual and graphic abilities of the idiot savant artist. Psychological Medicine 17: 79-90.

Pring L. (2005) Savant talent. Developmental Medicine and Child Neurology 47: 500503.

Pring L, Ryder N, Crane L, et al. (2010) Local and global processing in savant artists with autism. Perception 39: 1094-1103.

Raven J. (1956) Guide to using the Coloured Progressive Matrices, London: H.K. Lewis.

Raven J. (1960) Guide to using the Standard Progressive Matrices, London: H.K. Lewis.

Rimland B. (1978) Inside the mind of the autistic savant. Psychology Today 12: 69-80.

Sacks O. (1995) An anthropologist on Mars, London: Picador.

Selfe L. (1977) Nadia: A case of extraordinary drawing ability in an autistic child, London: Academic Press.

Selfe L. (1983) Normal and anomalous representational drawing ability in children, London: Methuen.

Sloboda JA, Hermelin B and O'Connor N. (1985) An exceptional musical memory. Music Perception 3: 155-170.

Sternberg RJ and Lubart TI. (1999) The Concept of Creativity: Prospects and Paradigms. In: Sternberg RJ (ed) Handbook of Creativity. Cambridge: Cambridge University Press, 3-15.

Torrance EP. (1972) Predictive Validity of the Torrance Tests of Creative Thinking. Journal of Creative Behavior 6: 236-252.

Torrance EP. (1974) The Torrance Tests of Creative Thinking: Technical-norms manual, Bensenville, IL: Scholastic Testing Services.

Treffert D. (2009) The savant syndrome: an extraordinary condition. A synopsis: past, present, future. Philosophical Transactions of the Royal Society B: Biological Sciences 364: 1351-1358.

Turner M. (1999) Generating Novel Ideas: Fluency Performance in High-Functioning and Learning Disabled Individuals with Autism. Journal of Child Psychology and Psychiatry 40: 189-201.

Wechsler D. (1999) Wechsler Adult Intelligence Scale - III. In: Corporation TP (ed). San Antonio: Harcourt Brace \& Company.

White S, Burgess P and Hill EL. (2009) Impairments in 'open-ended' executive function tests in autism. Autism Research 2: 138-147. 
Table 1: Participant demographics

$\begin{array}{cccccc}\text { Group } & & \text { Age } & \text { Gender } & \text { VIQ } & \text { PIQ } \\ \text { Savant } & \text { Mean (SD) } & 34.55(5.13) & 7: 2(\mathrm{~m}: \mathrm{f}) & 83.66(17.49) & 84.00(18.50) \\ \text { artists } & \text { Range } & 23-43 & & 56-111 & 55-114 \\ \text { ASD } & \text { Mean (SD) } & 32.22(6.59) & 7: 2(\mathrm{~m}: \mathrm{f}) & 78.78(14.79) & 82.33(16.59) \\ & \text { Range } & 22-43 & & 53-109 & 54-112 \\ \text { MLD } & \text { Mean (SD) } & 33.56(5.49) & 7: 2(\mathrm{~m}: \mathrm{f}) & 95.11(17.86) & 83.55(19.19) \\ & \text { Range } & 22-42 & & 63-117 & 53-115 \\ \text { Art students } & \text { Mean (SD) } & 17.44(.72) & 7: 2(\mathrm{~m}: \mathrm{f}) & 114.67(12.99) & 114.00(9.00) \\ & \text { Range } & 16-18 & & 95-125 & 94-120\end{array}$


Table 2: Mean (SD) fluency, originality, elaboration and flexibility scores on the incomplete and repeated figures tasks of the Torrance Test of Creative Thinking

$\begin{array}{lccc}\text { Savant } & \text { ASD } & \text { MLD } & \text { Art } \\ \text { artists } & & & \text { students }\end{array}$

$\begin{array}{llllll}\text { Fluency } & \text { Incomplete figures } & 8.40(2.13) & 8.00(2.92) & 9.11(2.03) & 10.00\end{array}$

$\begin{array}{ccccc} & & & & (0.00) \\ \text { Repeated figures } & 8.44(3.13) & 7.11(3.02) & 9.78(0.44) & 10.00 \\ & & & & (0.00) \\ \text { Total score } & 16.90 & 15.11 & 18.90 & 20.00 \\ & (4.70) & (5.40) & (2.31) & (0.00)\end{array}$

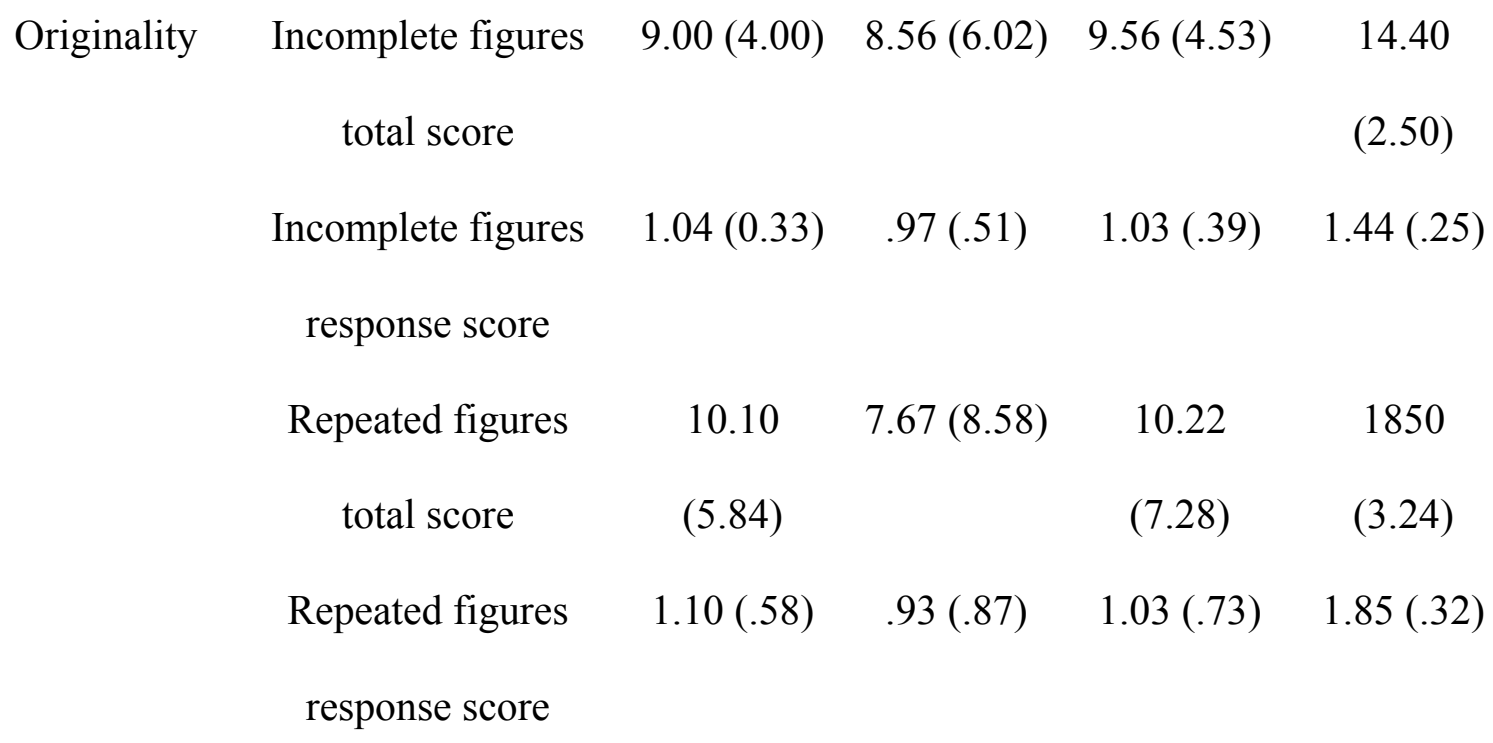

$\begin{array}{cccccc}\text { Elaboration } & \text { Incomplete figures } & 15.00 & 5.56(4.47) & 19.00 & 69.40 \\ \text { total score } & (11.53) & & (31.30) & (21.40) \\ & \text { Incomplete figures } & 1.69(1.08) & .67(.51) & 1.92(3.11) & 6.94(2.14) \\ & \text { response score } & & & & \end{array}$


Creativity in savant artists 25

$\begin{array}{cccccc}\begin{array}{c}\text { Repeated figures } \\ \text { total score }\end{array} & 26.56 & 6.67(8.53) & 9.44 & 65.70 \\ \text { Repeated figures } & 2.89(2.78) & .83(.95) & .95(1.44) & 6.57(3.22) \\ & \text { response score } & & & (14.37) & (29.35) \\ \text { Flexibility } & \text { Incomplete figures } & 7.00(1.50) & 5.78(2.68) & 7.00(2.45) & 8.90(1.29) \\ & \text { Repeated figures } & 5.67(2.50) & 4.44(5.89) & 5.89(3.06 & 9.10(1.29) \\ & \text { Total score } & 12.67 & 10.22 & 12.89 & 18.00 \\ & & (3.43) & (3.72) & (5.33) & (1.33)\end{array}$


Table 3: Mean (SD) fluency scores on the figural synthesis task

$\begin{array}{cccc}\text { Group } & \text { Two figures } & \text { Three figures } & \text { Four figures } \\ \text { Savant artists } & 8.56(3.54) & 6.89(5.16) & 5.11(2.42) \\ \text { ASD } & 7.77(4.27) & 5.33(2.12) & 2.78(2.33) \\ \text { MLD } & 15.44(8.49) & 11.11(8.35) & 8.56(6.48) \\ \text { Art students } & 14.00(5.48) & 12.00(6.42) & 8.56(4.55)\end{array}$


Table 4: Mean (SD) and percentage representational fluency scores on the figural synthesis task

Total representational fluency scores Percentage of representational scores

$\begin{array}{ccccccc}\text { Group } & \text { Two } & \text { Three } & \text { Four } & \text { Two } & \text { Three } & \text { Four } \\ & \text { figures } & \text { figures } & \text { figures } & \text { figures } & \text { figures } & \text { figures } \\ \text { Savant } & 8.11 & 4.78 & 3.11 & 95.3 & 73.1 & 55.9 \\ \text { artists } & (3.56) & (3.83) & (2.02) & (11.14) & (34.53) & (31.52) \\ \text { ASD } & 6.33 & 4.22 & 1.44 & 83.1 & 76.6 & 43.6 \\ & (3.67) & (1.78) & (3.46) & (19.84) & (32.36) & (44.01) \\ \text { MLD } & 10.33 & 7.44 & 4.44 & 73.1 & 69.6 & 61.1 \\ & (6.32) & (7.70) & (3.46) & (25.41) & (28.15) & (27.01) \\ \text { Art } & 13.78 & 12.67 & 8.44 & 97.5 & 94.0 & 97.1 \\ \text { students } & (5.67) & (4.50) & (4.36) & (4.48) & (6.33) & (6.73)\end{array}$


Table 5: Mean (SD) and percentage originality scores (as a function of representational fluency) on the figural synthesis task

Total originality scores

\begin{tabular}{ccccccc} 
& & & \multicolumn{4}{c}{ responses scored as original } \\
Group & Two & Three & Four & Two & Three & Four \\
& figures & figures & figures & figures & figures & figures \\
& 2.11 & 1.00 & 1.66 & 23.8 & 17.6 & 44.4 \\
Savant & $(1.54)$ & $(1.41)$ & $(1.87)$ & $(12.03)$ & $(21.57)$ & $(44.10)$ \\
artists & 1.11 & 1.11 & 0.33 & 18.1 & 22.5 & 16.6 \\
ASD & $(1.36)$ & $(1.26)$ & $(0.71)$ & $(19.69)$ & $(23.13)$ & $(35.63)$ \\
& 2.22 & 2.00 & 1.11 & 15.2 & 17.8 & 13.7 \\
MLD & $(2.49)$ & $(2.74)$ & $(1.96)$ & $(15.94)$ & $(17.78)$ & $(20.97)$ \\
& 3.55 & 3.00 & 3.78 & 21.9 & 25.1 & 47.0 \\
Art & $(3.39)$ & $(1.22)$ & $(1.85)$ & $(16.73)$ & $(10.06)$ & $(26.36)$
\end{tabular}


Figure captions

Figure 1: An example of work from a participating savant (now in the Stephen Wiltshire Gallery, London, UK).

Figure 2: Stimuli used in the Figural Synthesis Task and examples of acceptable outputs (an umbrella, a cat and a camera; in blue). 
Figure 1

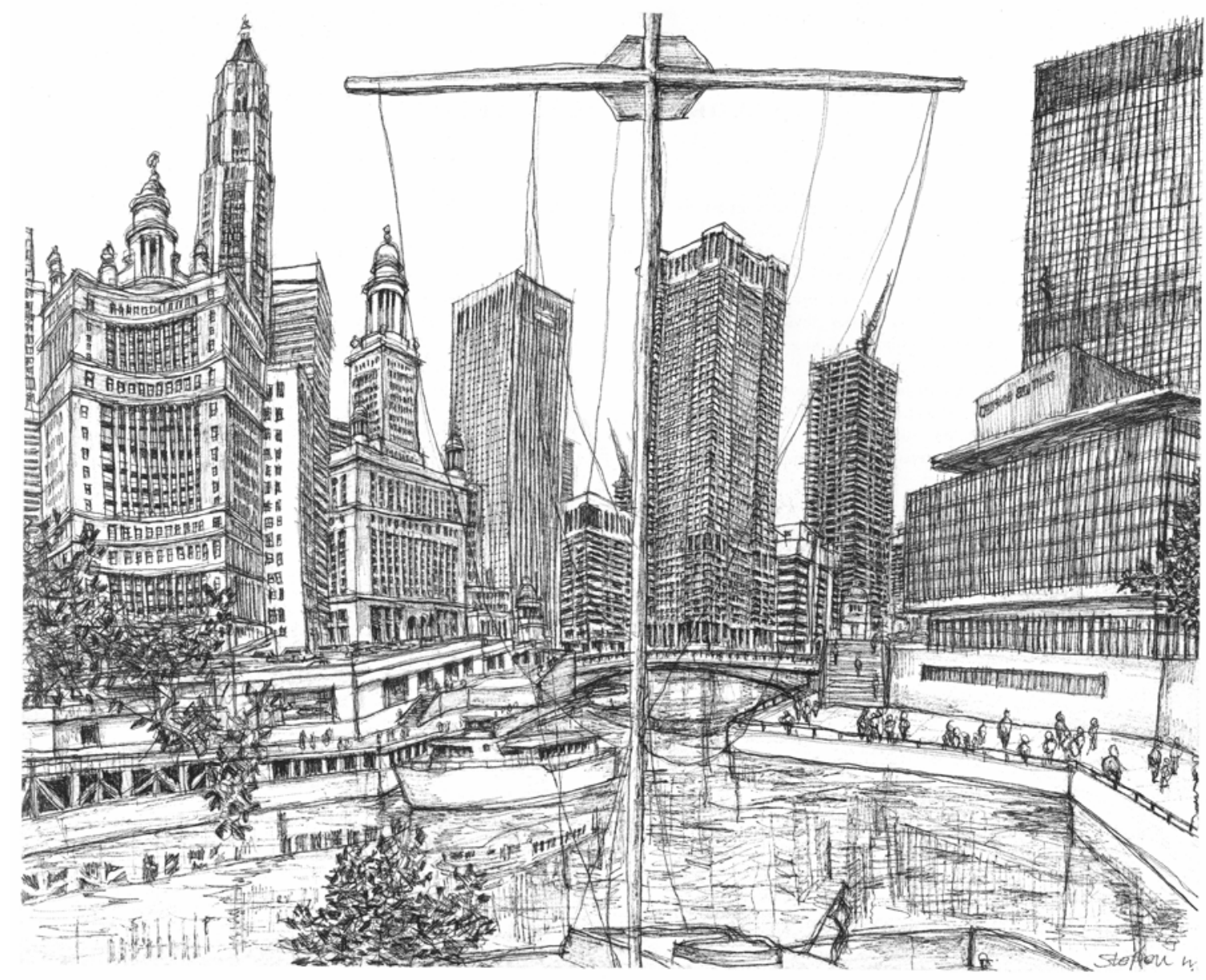


Figure 2
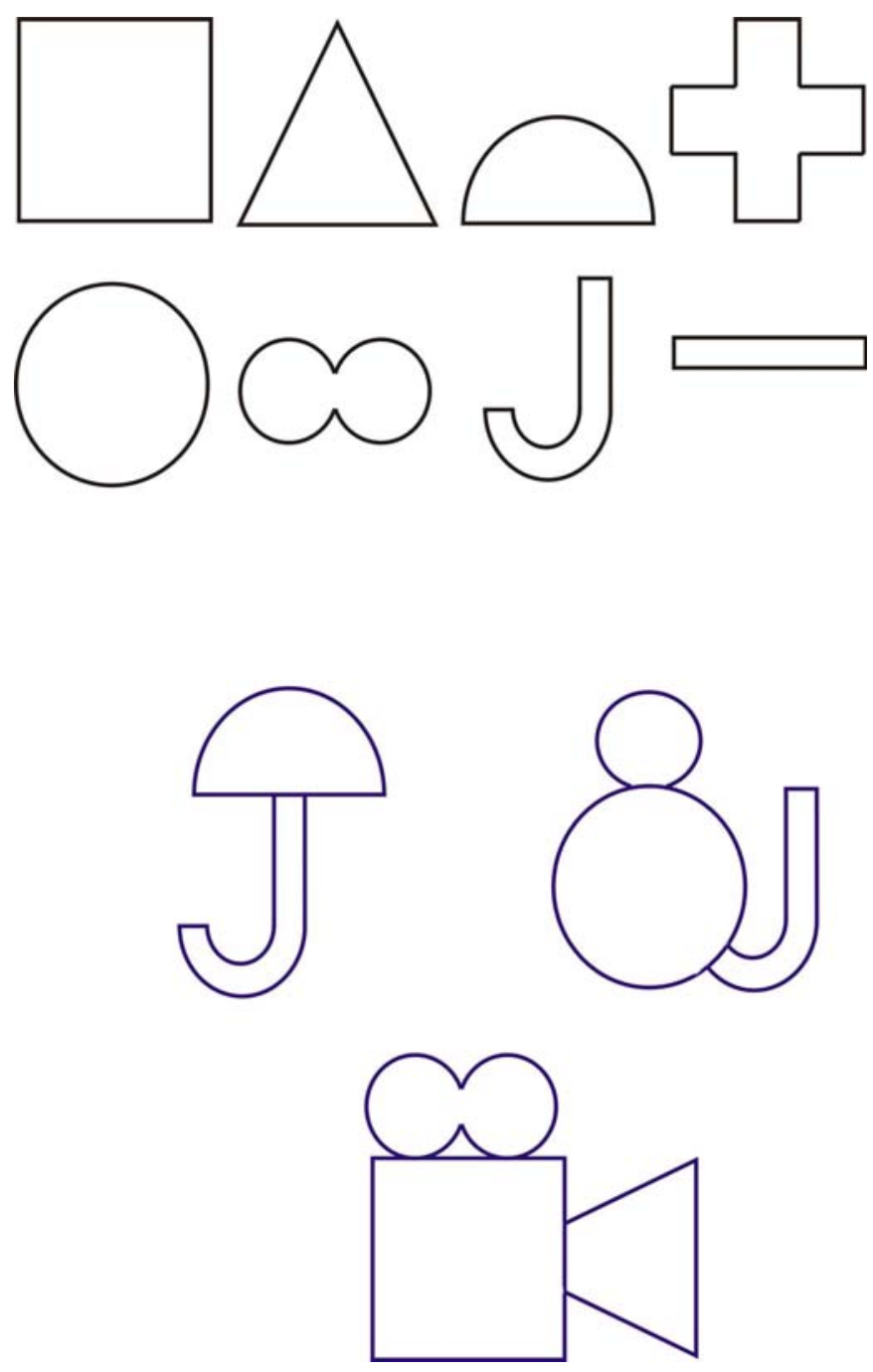